\title{
Studies on thermal decomposition and oxidation of $\mathrm{CoSb}_{3}$
}

\author{
Juliusz Leszczynski • Krzysztof T. Wojciechowski • \\ Andrzej Leslaw Malecki
}

Received: 13 October 2010/Accepted: 7 March 2011/Published online: 27 March 2011

(c) The Author(s) 2011. This article is published with open access at Springerlink.com

\begin{abstract}
Thermal durability of $\mathrm{CoSb}_{3}$ in vacuum, helium and air was investigated over the temperature range of $20-850{ }^{\circ} \mathrm{C}$. A scanning electron microscope (SEM) and $\mathrm{X}$-ray powder diffraction technique were used to investigate the microstructure and to carry out the phase analysis of the degradation products. The analysis of a non-isothermal and isothermal decomposition and oxidation of the $\mathrm{CoSb}_{3}$ powders and polycrystalline samples were performed using simultaneous TG/DTA technique. More detailed studies were carried out on the oxidation in the temperature range $400-600{ }^{\circ} \mathrm{C}$. It was established that the decomposition products are $\mathrm{CoSb}_{2}$ and a volatile antimony. In case of oxidation a complex three-layered scale is formed, consisting of $\mathrm{CoSb}_{2} \mathrm{O}_{4}, \mathrm{CoSb}_{2} \mathrm{O}_{6}$ and $\mathrm{Sb}_{2} \mathrm{O}_{4}$ layers. Both the decomposition and the oxidation kinetics are determined by a diffusion through the growing layers of products. The electrical resistivity and Seebeck coefficient measurements have been also performed on pure and oxidized samples, which showed a large influence of the oxidation on the electrical properties.
\end{abstract}

Keywords Skutterudite - Thermoelectric material · Oxidation · Decomposition - Thermal stability

\section{Introduction}

Skutterudites are compounds with the general formula $\mathrm{MX}_{3}$ where $\mathrm{M}$ is one of the transition metals $\mathrm{Co}$, $\mathrm{Rh}$ or $\mathrm{Ir}$

J. Leszczynski $(\varangle) \cdot$ K. T. Wojciechowski · A. L. Malecki Department of Inorganic Chemistry, Faculty of Materials Science and Ceramics, AGH University of Science and Technology, Al. Mickiewicza 30, 30-059 Cracow, Poland e-mail: juliusz.leszczynski@agh.edu.pl and $\mathrm{X}$ represents $\mathrm{P}$, As or $\mathrm{Sb}$. All nine possible compounds between the $\mathrm{M}$ and $\mathrm{X}$ elements crystallize with the bodycentered cubic structure (space group Im3) forming binary skutterudites. The skutterudite unit cell contains 32 atoms and can be regarded as an array of $\mathrm{MX}_{6}$ distorted octahedrons, sharing corners. This arrangement causes a formation of two large structural voids which can be completely or partially filled with small atoms, giving the so-called "filled" skutterudites. $\mathrm{CoSb}_{3}$ and relative compounds are the most promising thermoelectric materials among compounds with the skutterudite structure. Phase diagram for the Co-Sb system is well known [1]. $\mathrm{CoSb}_{3}$ is the $\delta$ phase, which is stable up to $874{ }^{\circ} \mathrm{C}$. Above this temperature it undergoes peritectic decomposition into liquid and $\mathrm{CoSb}_{2} \gamma$ phase, stable up to $936{ }^{\circ} \mathrm{C}$. In recent times numerous investigations of $\mathrm{CoSb}_{3}$-based materials showed that high values of thermoelectric figure of merit $Z T$ reaching 1.4 are possible to be obtained for filled skutterudites [2-5]. This makes skutterudites potential thermoelectric materials for thermoelectric generators working at elevated temperatures. During the intensive studies on these materials it was also found that skutterudites undergo oxidation and decomposition at temperatures above $400{ }^{\circ} \mathrm{C}$, the temperature is much lower than the peritectic temperature of $\mathrm{CoSb}_{3}$. The first report on the oxidation was given by Savtchuk et al. [6]. They noticed oxidation of $\mathrm{Co}_{1-x} \mathrm{Fe}_{x} \mathrm{Sb}_{3}$ thin films during annealing in argon atmosphere with some oxygen impurity. Products of this reaction were identified by XRD as $(\mathrm{Co}, \mathrm{Fe}) \mathrm{O}_{x}, \mathrm{FeSb}_{2} \mathrm{O}_{4}$ and $\mathrm{Sb}_{2} \mathrm{O}_{3}$. It was also observed that $\mathrm{Fe}$ impurity decreases the starting temperature of $\mathrm{CoSb}_{3}$ oxidation $\left(300{ }^{\circ} \mathrm{C}\right)$ compared to oxidation temperature of the pure $\mathrm{CoSb}_{3}$ samples $\left(380{ }^{\circ} \mathrm{C}\right)$. Hara et al. [7] were studying changes in $\mathrm{CoSb}_{3}$ during aging for $12-134 \mathrm{~h}$ in air at $600{ }^{\circ} \mathrm{C}$. They established that two layers of the oxidation products were formed on the surface of the 
samples. The outer layer was recognized to be a mixture of antimony oxides $\beta-\mathrm{Sb}_{2} \mathrm{O}_{4}, \mathrm{Sb}_{2} \mathrm{O}_{4}$ and $\mathrm{Sb}_{2} \mathrm{O}_{3}$, and the inner layer was $\mathrm{CoSb}_{2} \mathrm{O}_{6}, \mathrm{CoSb}_{2} \mathrm{O}_{4}, \mathrm{Sb}_{2} \mathrm{O}_{3}$ and $\beta-\mathrm{Sb}_{2} \mathrm{O}_{4}$. The thickness time dependence for the outer layer was found to obey the parabolic law. The inner layer and the total thickness time dependence were close to parabolic. They had also proposed a three-step mechanism of the oxidation: (i) antimony segregation on the surface, (ii) oxygen penetration into the region of antimony segregation, and (iii) reaction. For the oxidized sample they have observed a decrease of Hall carrier concentration $n$ from 3.4 to $2.7 \times 10^{26} \mathrm{~m}^{-3}$ and a subsequent increase of the resistivity resulting in a decrease of the overall thermoelectric performance. In our previous study [8] we have made a preliminary investigation on thermal oxidation of two skutterudite compounds $\mathrm{CoSb}_{3}$ and $\mathrm{CoP}_{3}$. It was established that the starting temperature for $\mathrm{CoSb}_{3}$ oxidation is $380{ }^{\circ} \mathrm{C}$ and for the $\mathrm{CoP}_{3}$ oxidation the starting temperature is $470{ }^{\circ} \mathrm{C}$. Oxidation products for $\mathrm{CoSb}_{3}$ were determined to be $\mathrm{Sb}_{2} \mathrm{O}_{4}, \mathrm{CoSb}_{2} \mathrm{O}_{6}$ and $\mathrm{CoSb}_{2} \mathrm{O}_{4}$, while for $\mathrm{CoP}_{3}$ they were found to be $\mathrm{Co}_{2} \mathrm{P}_{4} \mathrm{O}_{12}$ and a volatile $\mathrm{P}_{2} \mathrm{O}_{5} \cdot \mathrm{CoSb}_{3}$ oxidation proceeds in two stages and parabolic law was proposed to describe the oxidation kinetics of both stages. Contracting area equation was used for $\mathrm{CoP}_{3}$ oxidation to describe the experimental data.

The decomposition process was investigated by Snyder et al. and Calliat et al. [9]. They were studying the thermal stability of $\mathrm{CoSb}_{3}$ in a dynamic vacuum of $10^{-4} \mathrm{~Pa}$ at temperatures between 600 and $700{ }^{\circ} \mathrm{C}$. They have observed that $\mathrm{CoSb}_{3}$ decomposes to $\mathrm{CoSb}_{2}$ and $\mathrm{CoSb}$, which form layers on the sample surface, and to a volatile antimony. The reported starting temperature of the decomposition was $575{ }^{\circ} \mathrm{C}$. The time dependence of the discussed process was found to be parabolic-like and therefore they suggested it is controlled by the antimony diffusion.

The preliminary results of the studies on the $\mathrm{CoSb}_{3}$ thermal stability show that $\mathrm{CoSb}_{3}$ and related compounds undergo oxidation and decomposition in the whole range of their optimum thermoelectric properties. Therefore, determination of their thermal durability in air and in an inert atmosphere is a very important issue.

\section{Experimental}

Synthesis

Cobalt triantimonide powder was prepared through a direct solid-state reaction of the elements. A stoichiometric mixture of cobalt (purity-99.9\%) and antimony (99.999\%) powders was ground and enclosed in quartz ampoules under argon atmosphere. The ampoules were heated at $750{ }^{\circ} \mathrm{C}$ for 7 days. Then, the synthesized material was crushed, ground and sieved. The chemical and phase composition of the synthesized cobalt triantimonide was studied by means of various techniques. Chemical analysis performed by means of ICP-AES (Inductively Coupled Plasma Atomic Emission Spectroscopy, Perkin-Elmer Plasma 400) has confirmed that stoichiometric compounds were produced. Electron microscopic observations were made with JEOL JSM-840 scanning electron microscope equipped with EDS probe. The phase composition was determined using X'pert Philips diffractometer with $\mathrm{Ni}$ filtered $\mathrm{Cu}_{\mathrm{K} \alpha}$. These measurements confirmed that homogeneous cobalt triantimonide with the skutterudite structure was synthesized. The synthesized powder was used for preparation of polycrystalline samples and for thermal analysis studies.

\section{Sintering}

Polycrystalline samples were prepared by uniaxial hot pressing technique. Powder was sintered in a graphite die under the pressure of $30 \mathrm{MPa}$ at $770{ }^{\circ} \mathrm{C}$ for $1 \mathrm{~h}$. As a result samples with diameter of $\varnothing=10$ and $15 \mathrm{~mm}$ high were obtained. The samples were $99.8 \%$ of the theoretical density. Chemical and phase composition were confirmed to be the same as in the starting powders. More details about the synthesis and sintering of $\mathrm{CoSb}_{3}$ can be found in our earlier publications [10]. In order to prepare samples for degradation studies the samples were cut with a diamond saw and polished.

Thermal decomposition and oxidation studies and the decomposition and oxidation products analysis

The dense (99.8\%), polycrystalline samples of $\mathrm{CoSb}_{3}$ were thermally treated under vacuum of $10^{-3} \mathrm{~Pa}$ in sealed quartz ampoules, or in quartz crucibles in air at temperature range from 600 to $700{ }^{\circ} \mathrm{C}$ for 50 to $130 \mathrm{~h}$. Non-isothermal DTA and TG measurements of the oxidation and the decomposition of the powders were carried out in air or helium atmosphere in a SDT 2960 TA Instruments apparatus. A typical sample mass was $50 \pm 2 \mathrm{mg}$. Chemical and phase composition as well as morphology of the decomposition and oxidation products were determined using the same methods as those used in the initial characterization of materials. A marker experiment has been performed for $\mathrm{CoSb}_{3}$ oxidation. A $0.03 \mathrm{~mm}$ platinum wire was wound around a specimen. The specimen was oxidized at $600{ }^{\circ} \mathrm{C}$ for $50 \mathrm{~h}$. Optical microscopy was used to determine the marker position in the scale.

\section{Oxidation kinetics}

The $\mathrm{CoSb}_{3}$ oxidation kinetics was determined by isothermal gravimetric measurements carried out in a modified 
DTA/TG apparatus of the Paulik-Paulik-Erdey system. The apparatus was equipped with Sartorius balance (accuracy $10^{-4} \mathrm{~g}$ ) and computer data acquisition and control system. Measurements were conducted on the pulverized $\mathrm{CoSb}_{3}$ in dynamic air atmosphere $\left(20 \mathrm{dm}^{3} / \mathrm{h}\right)$ in the temperature range of $430-550{ }^{\circ} \mathrm{C}$. The microscopic observations revealed powder average grain size of $15 \mu \mathrm{m}$. The powder was spilled onto a quartz plate in a form of thin layer, to eliminate the influence of gaseous oxygen transport on overall process kinetics. Before starting the experiment the furnace of the DTA/TG apparatus was heated to the desired temperature and held at this temperature for $30 \mathrm{~min}$. Then the furnace was opened, the crucible filled with the powder was placed inside, and the furnace was closed. During closing of the furnace the data acquisition system was initialized and the measurement was started.

\section{Electrical properties measurements}

Electric conductivity, Seebeck coefficient and thermal conductivity were measured between room temperature and $300{ }^{\circ} \mathrm{C}$. Electrical conductivity was measured using a DC four-probe technique with current applied alternately in both directions. Thermal conductivity measurements were made in the same apparatus using the steady state constant heat flow method. Error of the thermal conductivity was estimated to be less than $7 \%$. Seebeck coefficient measurement was performed simultaneously with the thermal conductivity measurement.

\section{Results}

\section{Decomposition}

In order to determine temperatures of cobalt triantimonide decomposition and oxidation, non-isothermal DTA and TG measurements were performed. The observed decomposition curves are shown in Fig. 1. Cobalt triantimonide decomposition in helium proceeds in several stages. All of the stages are endothermic and accompanied by a loss of weight. Because the decomposition proceeds moderately slowly, therefore the DTA signal is flattened and the peaks attributed to first stages are broadened and overlapping. For this reason, mainly TG and DTG data were used to determine the onset temperatures. Cobalt triantimonide decomposition in helium starts at about $420{ }^{\circ} \mathrm{C}$ Following four DTG peaks were observed, with onset temperatures at approximately 580, 691, 871 and $929^{\circ} \mathrm{C}$. On the basis of thermodynamic data, the increase of decomposition rate at $580{ }^{\circ} \mathrm{C}$ with the peak maxima at $640{ }^{\circ} \mathrm{C}$ could be attributed to faster antimony transport or evaporation due to exceeding the melting point of antimony $\left(630^{\circ} \mathrm{C}\right)$. For the next peak with the onset temperature $691^{\circ} \mathrm{C}$, we cannot ascribe it to any phenomena and it probably corresponds to a faster decomposition mechanism, i.e. activation of a faster $\mathrm{Sb}$ diffusion path. Subsequently the increases of decomposition rates at 875 and $930{ }^{\circ} \mathrm{C}$ can be ascribed to thermodynamic stability limits of skutterudite $\delta \mathrm{CoSb}_{3}$ $\left(874{ }^{\circ} \mathrm{C}\right)$ and $\gamma \mathrm{CoSb}_{2}\left(931{ }^{\circ} \mathrm{C}\right)$ phases, respectively. All DTG peaks below the peritectic temperature of $\mathrm{CoSb}_{2}$ correspond to decomposition of $\mathrm{CoSb}_{3}$.

SEM observations (Fig. 2a) of the $\mathrm{CoSb}_{3}$ samples annealed in vacuum at $700{ }^{\circ} \mathrm{C}$ showed that their surface was completely covered by a dense network of canals and pores. These features appear to coincide with grain boundaries. In a cross-section SEM micrograph (Fig. 2b) of a sample heated for $50 \mathrm{~h}$, the visible "labyrinthine system" has an average size of $100 \mu \mathrm{m}$. A Sb depletion inside the $\mathrm{CoSb}_{3}$ substrate can also be noticed as small pores. The quartz ampoules used for the decomposition studies were covered by a metallic mirror after the experiments. A chemical analysis indicated that this mirror consisted of pure antimony, hence, the volatile product of the cobalt triantimonide decomposition is antimony. An EDS line analysis (Fig. 3), starting from the skutterudite substrate through the porous product layer, revealed that the cobalt/antimony ratio increases towards the surface. X-ray diffraction results presented in Fig. 4 show that under argon atmosphere at $700{ }^{\circ} \mathrm{C}$ cobalt triantimonide decomposes to $\mathrm{CoSb}_{2}$, which covers the surface of the specimen. Taking into account all the collected results we proposed the following decomposition reaction below the peritectic temperature:

$\mathrm{CoSb}_{3(s)} \rightarrow \mathrm{CoSb}_{2(s)}+1 / 4 \mathrm{Sb}_{4(g)}$

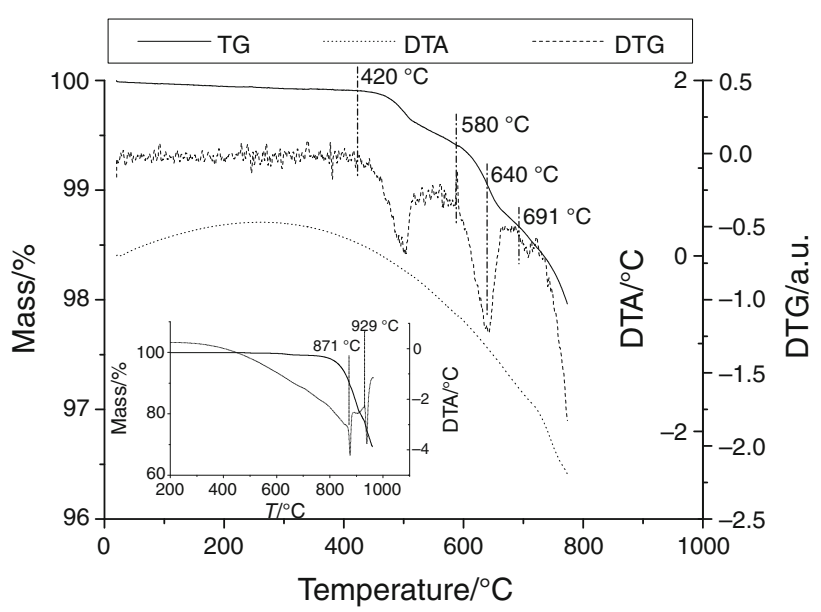

Fig. 1 DTG, TG and DTA curves for $\mathrm{CoSb}_{3}$ decomposition in helium (sample mass $=50 \mathrm{mg}$, heating rate $10{ }^{\circ} \mathrm{C} / \mathrm{min}$ ). The inserted plot presents TG and DTA curves for the $\mathrm{CoSb}_{3}$ decomposition in helium at heating rate $20{ }^{\circ} \mathrm{C} / \mathrm{min}$ (sample mass $=50 \mathrm{mg}$ ) 
A series of TG and DTA decomposition experiments in flowing helium was performed at various heating rates. The DTA/TG study was restricted solely to a mass-loss of $2 \%$ in order to reduce the undesirable influence of the volatile antimony on the DTA apparatus. For this reason, the kinetic analysis was not possible. Microscopic observations suggest that the parabolic-like dependence observed by Snyder and Caillat [9] is a sensible reason to assume that the decomposition is limited by an outward antimony diffusion, and therefore the decomposition kinetics can be described by the parabolic law. The established decomposition products are in partial agreement with the results of Snyder et al. [9]. They have observed the presence of $\mathrm{CoSb}$, besides $\mathrm{CoSb}_{2}$ as a product of $\mathrm{CoSb}_{3}$ decomposition. Our result is probably an effect of higher $\mathrm{Sb}$ vapour pressure during the experiment. The $\mathrm{Sb}_{4}$ vapour pressure was below the $\mathrm{CoSb}_{3}$ decomposition pressure, but higher than $\mathrm{CoSb}_{2}$ decomposition pressure, which prevented the cobalt diantimonide decay to $\mathrm{CoSb}$. The other discrepancy is the starting temperature of the decomposition. The temperature observed in this study was more than $150{ }^{\circ} \mathrm{C}$ lower compared to Snyder and Caillat results. One of the possible explanations is the use of powder samples instead of bulk samples in our TG/DTA investigations. This result means that $\mathrm{CoSb}_{3}$ is more susceptible to decomposition than it was found by Snyder and Caillat, and it means that decomposition is an important issue to cope with in application of this material.

\section{Oxidation}

Cobalt triantimonide TG and DTA oxidation curves are presented in Fig. 5. The oxidation starts at about $371{ }^{\circ} \mathrm{C}$ and proceeds in several stages. The rate of mass change is greater than during the decomposition. DTA peaks are sharp and well separated, however, the corresponding features on the TG curve are not so evident. Exothermic DTA peaks correspond to the rapid increase of the oxidation rate starting at about 583, 655 and $740{ }^{\circ} \mathrm{C}$. All DTA peaks are accompanied by equivalent DTG peaks and correspond to $\mathrm{CoSb}_{3}$ oxidation. Comparing these temperatures with thermodynamic data of possible oxidation
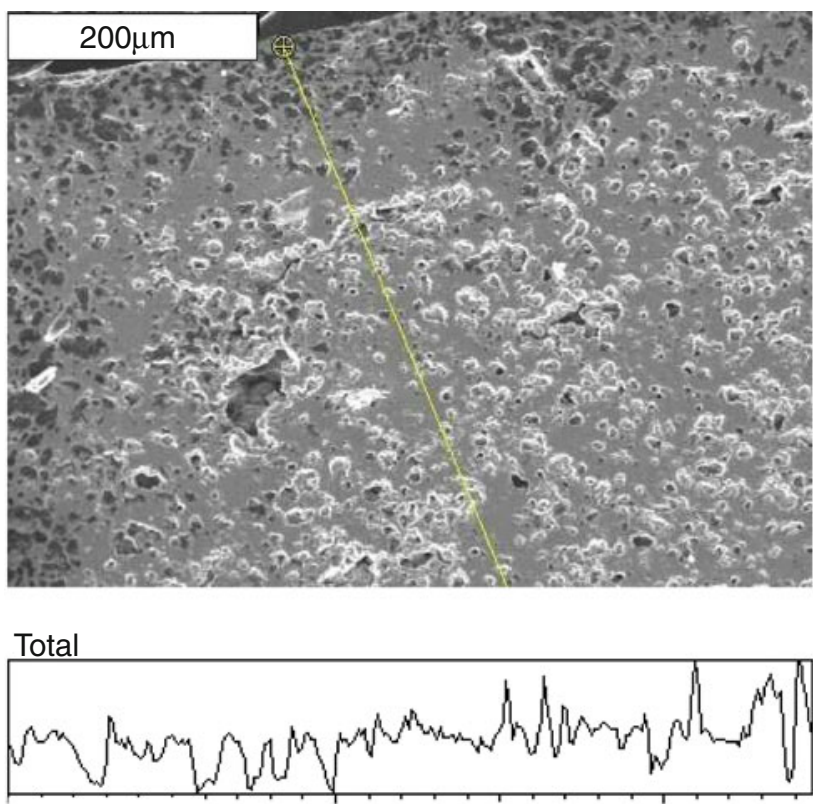

$\mathrm{Sb}$
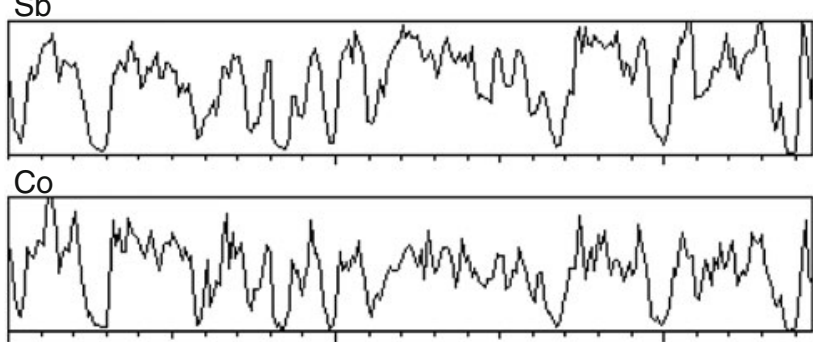

Fig. 3 A SEM cross-section micrograph of a $\mathrm{CoSb}_{3}$ sample decomposed in vacuum at $700{ }^{\circ} \mathrm{C}$ for $50 \mathrm{~h}$ with a line $\mathrm{EDS}$ chemical analysis results

products it can be noticed that similar temperatures occur in case of $\mathrm{Sb}_{2} \mathrm{O}_{3}$, which, between 570 and $600{ }^{\circ} \mathrm{C}$, undergoes a phase transition from a cubic structure of senarmontite $\alpha-\mathrm{Sb}_{2} \mathrm{O}_{3}$ to an orthorhombic structure of valentinite $\beta-\mathrm{Sb}_{2} \mathrm{O}_{3}$ [11] having a melting point at $650{ }^{\circ} \mathrm{C}$. Above $510{ }^{\circ} \mathrm{C} \alpha-\mathrm{Sb}_{2} \mathrm{O}_{3}$ reacts with oxygen, yielding diantimony tetraoxide $\alpha-\mathrm{Sb}_{2} \mathrm{O}_{4}$. The phase transition between $\alpha-\mathrm{Sb}_{2} \mathrm{O}_{3}$ and $\beta-\mathrm{Sb}_{2} \mathrm{O}_{3}$ is also possible at lower temperatures, i.e. during high-energy ball milling [12]. It is worth noting that in the analysed temperature range cubic diantimony (III) trioxide is volatile. Its sublimation was observed above
Fig. 2 Scanning electron micrographs of $\mathrm{CoSb}_{3}$ bulk sample after decomposition in vacuum at $700{ }^{\circ} \mathrm{C}$ for $50 \mathrm{~h}$, a a surface of the sample, $\mathbf{b}$ a crosssection of the sample
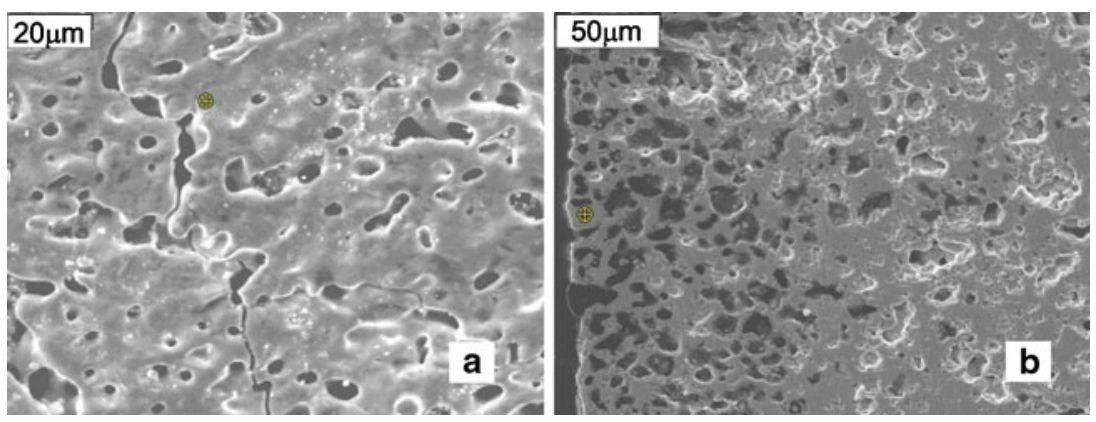


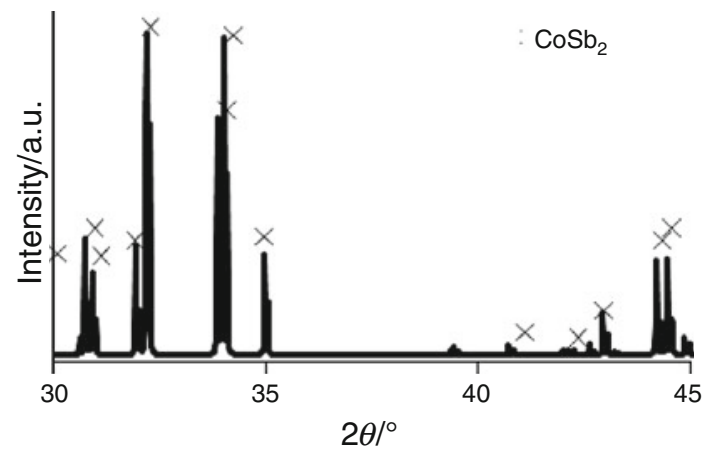

Fig. 4 X-ray diffraction pattern of $\mathrm{CoSb}_{3}$ surface after decomposition in vacuum at $700{ }^{\circ} \mathrm{C}\left(x-\mathrm{CoSb}_{2}\right)$

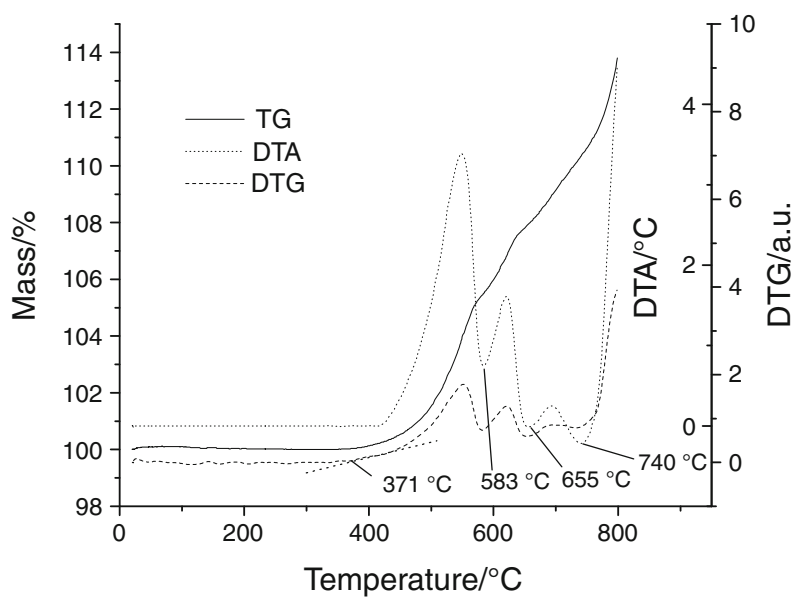

Fig. 5 TG, DTG and DTA results for $\mathrm{CoSb}_{3}$ powder oxidation in air (sample mass $120 \mathrm{mg}$, heating rate $10^{\circ} \mathrm{C} / \mathrm{min}$ )

$450{ }^{\circ} \mathrm{C}$ especially in inert atmospheres [11] and this process becomes very fast at about $550{ }^{\circ} \mathrm{C}$. The $\beta-\mathrm{Sb}_{2} \mathrm{O}_{3}$ is less volatile but it is oxidized to $\alpha-\mathrm{Sb}_{2} \mathrm{O}_{4}$ at temperatures lower than for $\alpha-\mathrm{Sb}_{2} \mathrm{O}_{3}\left(400-500{ }^{\circ} \mathrm{C}\right)$ [12]. For the peaks starting at 655 and $740{ }^{\circ} \mathrm{C}$ we cannot ascribe them to any specific phase transition or phenomena. We suppose these peaks indicate a change of the rate limiting step or creation of a new, faster reaction path, possibly related with some change of thermodynamic properties of the oxidation products. It can be related to a phase transition of $\alpha-\mathrm{Sb}_{2} \mathrm{O}_{4}$ to $\beta-\mathrm{Sb}_{2} \mathrm{O}_{4}$. Filipek and Dabrowska [13] have observed that for the pure $\alpha-\mathrm{Sb}_{2} \mathrm{O}_{4}$ transition to $\beta-\mathrm{Sb}_{2} \mathrm{O}_{4}$ occurs at $1,080{ }^{\circ} \mathrm{C}$, but in a presence of $\mathrm{ZnO}$ the phase transition temperature was decreased to $1,000{ }^{\circ} \mathrm{C}$. Moreover, in the case of presence of molybdenum oxide $\mathrm{MoO}_{3}$ [12] it was observed that $\alpha-\mathrm{Sb}_{2} \mathrm{O}_{4}$ was transformed into $\beta-\mathrm{Sb}_{2} \mathrm{O}_{4}$ at temperature as low as $700{ }^{\circ} \mathrm{C}$. A total oxidation mass gain was determined for different temperatures and compared with the possible products. The measured and calculated mass gain values are presented in Tables 1 and 2. It can be noticed that up to $650{ }^{\circ} \mathrm{C}$ the weight gain is from 22.12 to
$22.7 \%$ comparable with the formation of $\mathrm{CoS}$ $\mathrm{b}_{2} \mathrm{O}_{4}+\mathrm{Sb}_{2} \mathrm{O}_{4}$, and for higher temperatures 700 and $750{ }^{\circ} \mathrm{C}$ the mass gain rises up to $25.4 \%$, which means that formation of both cobalt antimonates $\mathrm{CoSb}_{2} \mathrm{O}_{4}$ and $\mathrm{CoSb}_{2} \mathrm{O}_{6}$ as well as antimony oxide $\mathrm{Sb}_{2} \mathrm{O}_{4}$ can be expected. Figure 6 shows the time dependence of the mass gain during these experiments. Different oxidation time dependences were observed for lower $\left(400-650{ }^{\circ} \mathrm{C}\right)$ and higher temperatures $\left(700-750{ }^{\circ} \mathrm{C}\right)$. At lower temperatures a systematic mass gain is observed during the whole oxidation time. At higher temperatures, after the first period of a fast mass gain, a mass loss occurs, which is again followed by the next stage of a mass gain. Probably, this mass loss during oxidation can be attributed to $\mathrm{Sb}_{2} \mathrm{O}_{3}$ evaporation, as the mass loss is observed above $\beta-\mathrm{Sb}_{2} \mathrm{O}_{3}$ melting point $\left(650^{\circ} \mathrm{C}\right)$.

XRD measurements for completely oxidized $\mathrm{CoSb}_{3}$ powders at 550 and $650{ }^{\circ} \mathrm{C}$ (Fig. 7) indicate that in each examined temperature the main oxidation products are $\alpha-\mathrm{Sb}_{2} \mathrm{O}_{4}, \mathrm{CoSb}_{2} \mathrm{O}_{6}$ and $\mathrm{CoSb}_{2} \mathrm{O}_{4}$. It means that for lower

Table 1 Measured weight gains of completely oxidized $\mathrm{CoSb}_{3}$ at different temperatures

\begin{tabular}{llllll}
\hline Temperature $/{ }^{\circ} \mathrm{C}$ & 500 & 575 & 630 & 700 & 750 \\
Mass-gain/\% & 22.12 & 22.08 & 22.7 & 25.4 & 25.5 \\
\hline
\end{tabular}

Table 2 Theoretical mass-gain for various $\mathrm{CoSb}_{3}$ oxidation products

\begin{tabular}{lc}
\hline Products & Mass-gain/\% \\
\hline $\mathrm{CoSb}_{2} \mathrm{O}_{4}+$ volatile $\mathrm{Sb}_{2} \mathrm{O}_{3}$ & -13.6 \\
$\mathrm{CoSb}_{2} \mathrm{O}_{6}+$ volatile $\mathrm{Sb}_{2} \mathrm{O}_{3}$ & -6.1 \\
$\mathrm{CoSb}_{2} \mathrm{O}_{4}+1 / 2 \mathrm{Sb}_{2} \mathrm{O}_{4}$ & 22.6 \\
$1 / 2 \mathrm{CoSb}_{2} \mathrm{O}_{6}+1 / 2 \mathrm{CoSb}_{2} \mathrm{O}_{4}+1 / 2 \mathrm{Sb}_{2} \mathrm{O}_{4}$ & 26.4 \\
$\mathrm{CoSb}_{2} \mathrm{O}_{6}+1 / 2 \mathrm{Sb}_{2} \mathrm{O}_{4}$ & 30.1 \\
\hline
\end{tabular}

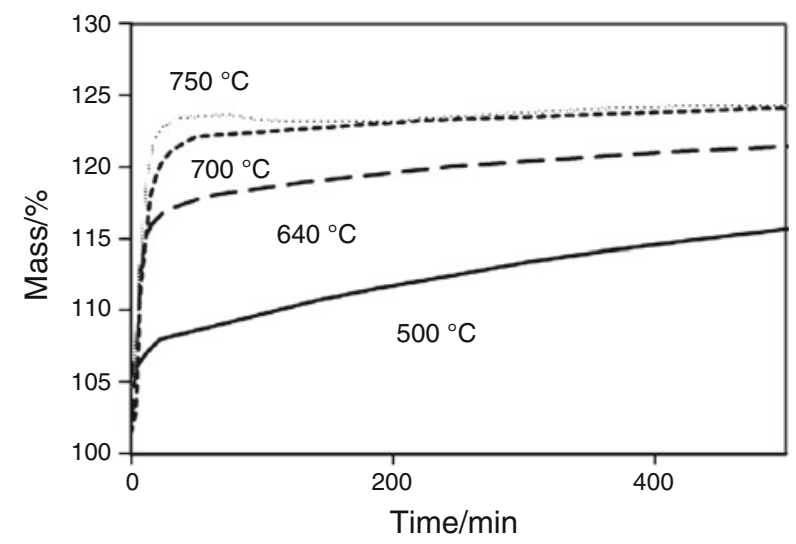

Fig. 6 Isothermal oxidation curves of $\mathrm{CoSb}_{3}$ powder in air at different temperatures 


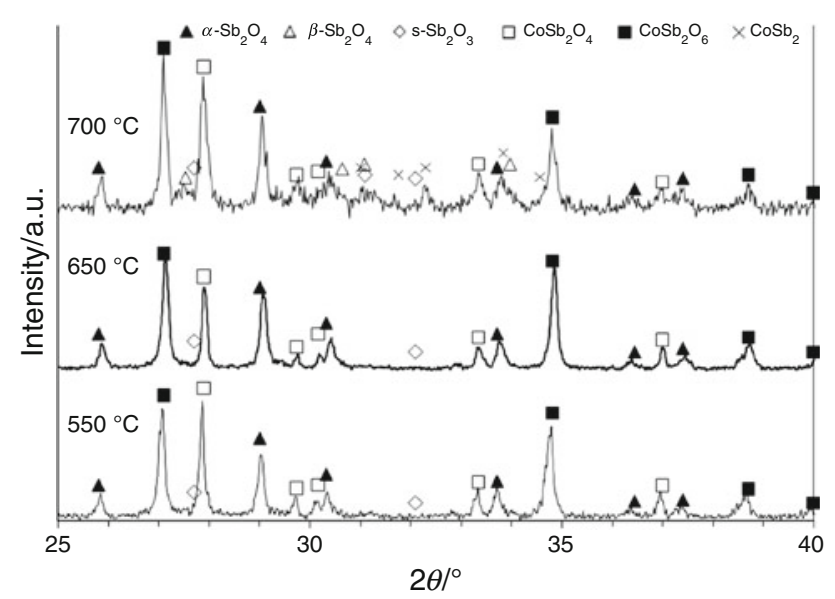

Fig. 7 XRD patterns of completely oxidized $\mathrm{CoSb}_{3}$ powders at different temperatures

temperatures $\left(500-650{ }^{\circ} \mathrm{C}\right)$, where the mass gain is comparable with formation of $\mathrm{CoSb}_{2} \mathrm{O}_{4}$ and $\alpha-\mathrm{Sb}_{2} \mathrm{O}_{4}$, in fact, $\mathrm{CoSb}_{2} \mathrm{O}_{6}$ and some volatile antimony oxide $\mathrm{Sb}_{2} \mathrm{O}_{3}$ are also produced. A special case in Fig. 7 is a diffraction pattern for the powder oxidized at $700{ }^{\circ} \mathrm{C}$. This sample was supposed to be completely oxidized but XRD showed it had not been entirely oxidized and some intermediate products like $\mathrm{CoSb}_{2}$, cubic $\alpha-\mathrm{Sb}_{2} \mathrm{O}_{3}$ and $\beta-\mathrm{Sb}_{2} \mathrm{O}_{4}$ were noticeable. XRD investigations on the $\mathrm{CoSb}_{3}$ surface after removing antimony oxide and cobalt antimonates layers were made in order to determine if $\mathrm{CoSb}_{2}$ phase is formed on the $\mathrm{CoSb}_{3} / \mathrm{CoSb}_{2} \mathrm{O}_{4}$ interface. XRD pattern of pure $\mathrm{CoSb}_{3}$ without any other reflections was observed. SEM observations and $\mathrm{EDS}$ analysis did not indicate $\mathrm{CoSb}_{2}$ existence at the $\mathrm{CoSb}_{3} / \mathrm{CoSb}_{2} \mathrm{O}_{4}$ interface either. These results suggest that decomposition to $\mathrm{CoSb}_{2}$ can be a competitive process, but only in the higher range of the examined temperatures. For the remaining samples the observed quantity of phases other than $\alpha-\mathrm{Sb}_{2} \mathrm{O}_{4}, \mathrm{CoSb}_{2} \mathrm{O}_{6}$ and $\mathrm{CoSb}_{2} \mathrm{O}_{4}$ was below $1 \%$. Calculations of $\mathrm{Sb}_{2} \mathrm{O}_{3}$ amount, on the basis of weight gain results and preliminary XRD quantitative analysis, showed that no more than $1.5 \%$ of antimony forms volatile $\mathrm{Sb}_{2} \mathrm{O}_{3}$. However, during XRD analysis of the surface of oxidized polycrystalline samples, the presence of senarmontite, a cubic polymorph of $\mathrm{Sb}_{2} \mathrm{O}_{3}$, was observed. Due to a strong grain orientation it was impossible to judge the content of the $\mathrm{Sb}_{2} \mathrm{O}_{3}$ phase. It is very probable that $\mathrm{Sb}_{2} \mathrm{O}_{3}$ is an intermediate oxidation product which during the course of reaction is oxidized to $\alpha-\mathrm{Sb}_{2} \mathrm{O}_{4}$ and therefore, it is not detected in the completely oxidized specimens. These results show that oxidation of $\mathrm{CoSb}_{3}$ is a complex process and beside the main reactions other competitive reactions can take place. In further considerations the three main products $\alpha-\mathrm{Sb}_{2} \mathrm{O}_{4}, \mathrm{CoSb}_{2} \mathrm{O}_{6}$ and $\mathrm{CoSb}_{2} \mathrm{O}_{4}$ are generally taken into account.

The scale microstructure and morphology were examined by scanning electron microscopy SEM and optical microscopy in reflected light. A SEM image (Fig. 8a) of $\mathrm{CoSb}_{3}$ surface, heated in air at $700{ }^{\circ} \mathrm{C}$ for 2 days, shows that oxidation leads to creation of dense scale with a wrinkled surface. Because the size of the hills and valleys network on the surface is similar to the grain size in the polycrystalline sample (see Fig. 8b), a reasonable explanation is that these features are located over grain boundaries crossing the sample surface, where the mass transport is enhanced. EDS analysis of the surface indicates it contains almost only antimony and oxygen. Cross-section micrographs for different oxidation times presented in Fig. 9a have revealed that scale morphology is complex and for long-term oxidation it is multilayered with two or three products layers. It is also worth to notice that some kind of probably antimony depletion can be observed inside the $\mathrm{CoSb}_{3}$ substrate, manifested by a presence of porosity not observed in the initial samples. For thin layers $(<7 \mu \mathrm{m})$ formed during short time oxidation the atomic ratios are uniform inside the scale in the precision of the EDS method. In cases of longer oxidation times, a thick scale $(>10 \mu \mathrm{m})$ splits up and two layers with different composition can be distinguished by the EDS analysis. The line microanalysis ascertains that the surface layer (I) is composed mostly of antimony oxides and the inner layer (II) which contains cobalt, antimony and oxygen, forming cobalt antimonates and possibly antimony oxides. It is evident that thickness of this scale is not uniform (Figs. 8, 9a). The largest
Fig. 8 SEM micrographs of oxidized $\mathrm{CoSb}_{3}$ pellets (air, $700{ }^{\circ} \mathrm{C}, 48 \mathrm{~h}$ ). a Surface of the sample, b cross-section through the surface of the sample
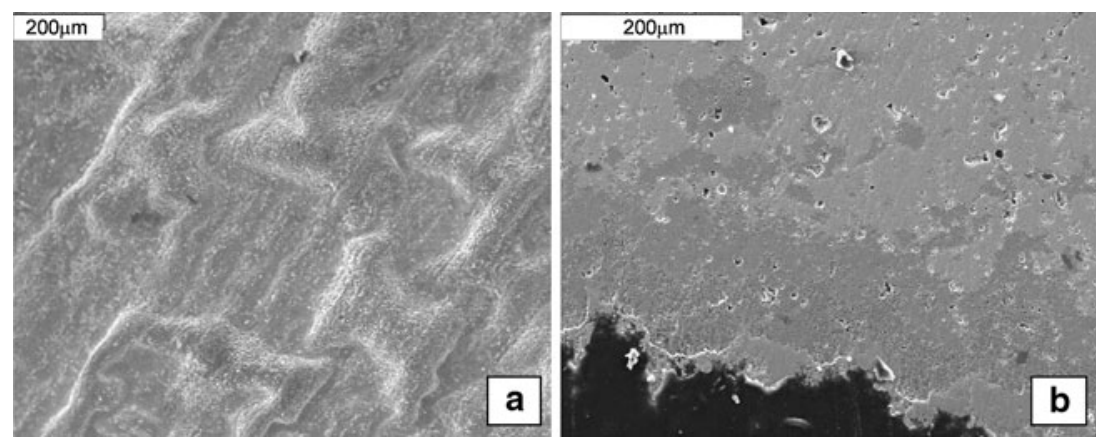
Fig. 9 SEM micrographs of cross-sections of oxidized $\mathrm{CoSb}_{3}$ samples surface with results of EDS analysis (air, $600{ }^{\circ} \mathrm{C}, 2 \mathrm{~h}$ on the left side, $24 \mathrm{~h}$ on the right side)
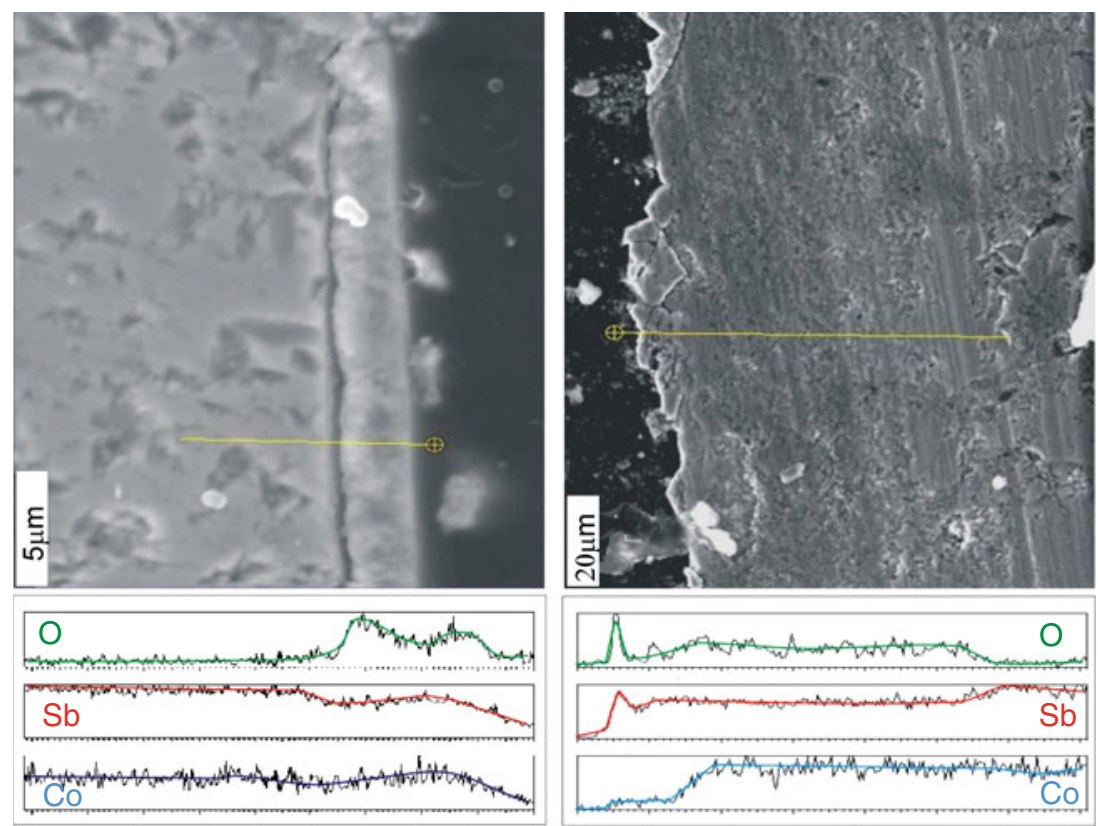

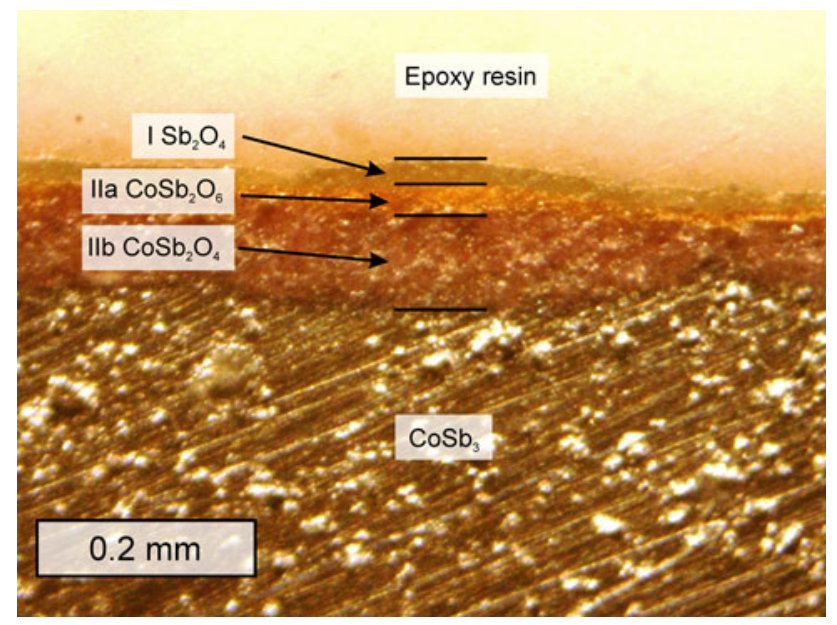

Fig. 10 Micrograph of a cross-section of an oxidized $\mathrm{CoSb}_{3}$ sample (air, $600{ }^{\circ} \mathrm{C}, 48 \mathrm{~h}$ )

differences of the thickness up to $300 \%$ were observed for the sample with an average scale thickness of $90 \mu \mathrm{m}$. Thus, the interface between the scale and $\mathrm{CoSb}_{3}$ substrate is not plane. The reaction front penetrates the substrate at grain boundaries where the high-diffusivity paths are present, and as a result some grains are separated from the substrate and surrounded by the oxidation products. In these places the scale thickness is higher and hills on the surface are formed, which can be observed in the micrographs of the oxidized surface. Optical micrographs presented in Fig. 10 show that actually in the thick scale three layers having different colours can be distinguished. The outer layer (I) of antimony oxides is a semi-transparent brown-yellowish. The inner-antimonate layer (II) consists of two layers having

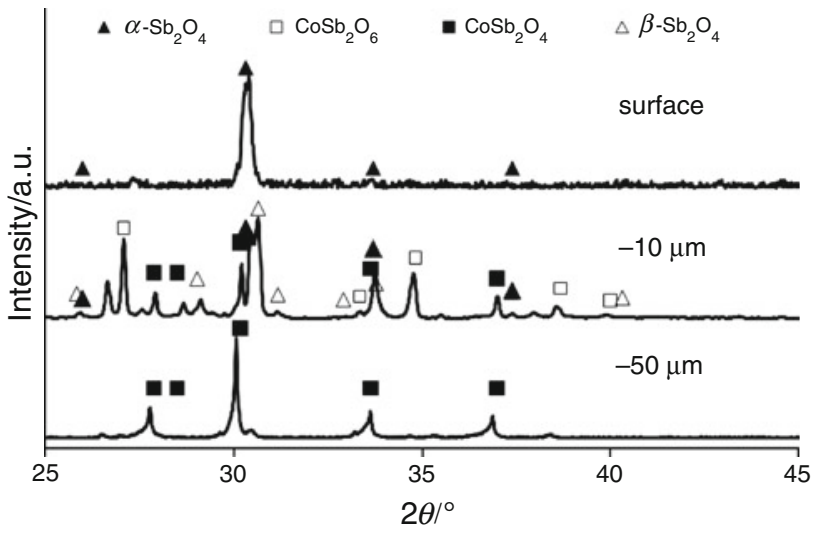

Fig. 11 X-ray diffraction XRD depth profile of a scale formed on $\mathrm{CoSb}_{3}$ surface after oxidation in the air at $650{ }^{\circ} \mathrm{C}$

different colours. The inner part of the antimonate layer is violet (IIa) and the outer (which is in the middle between the antimony oxide and violet cobalt antimonite) is orangeyellow (IIb). In order to determine a phase composition of the observed product layers X-ray diffraction depth profile was done on a long-term oxidized sample. XRD depth profile results (Fig. 11) confirmed that the scale consists of three main layers. The surface layer is composed of $\alpha$ $\mathrm{Sb}_{2} \mathrm{O}_{4}$. The internal layers consists mainly of cobalt antimonates $\mathrm{CoSb}_{2} \mathrm{O}_{6}$ and $\mathrm{CoSb}_{2} \mathrm{O}_{4}$. Because of the rough sample surface after the oxidation and thickness differences described earlier, it was impossible to separate pure patterns of $\mathrm{CoSb}_{2} \mathrm{O}_{6}$ layer. However, it was observed that $\mathrm{CoSb}_{2} \mathrm{O}_{4}$ content increases towards the $\mathrm{CoSb}_{3}$ substrate. This indicates that $\mathrm{CoSb}_{2} \mathrm{O}_{4}$ lays on the $\mathrm{CoSb}_{3}$ substrate and $\mathrm{CoSb}_{2} \mathrm{O}_{6}$ is placed between $\mathrm{CoSb}_{2} \mathrm{O}_{4}$ and $\mathrm{Sb}_{2} \mathrm{O}_{4}$. Similar 


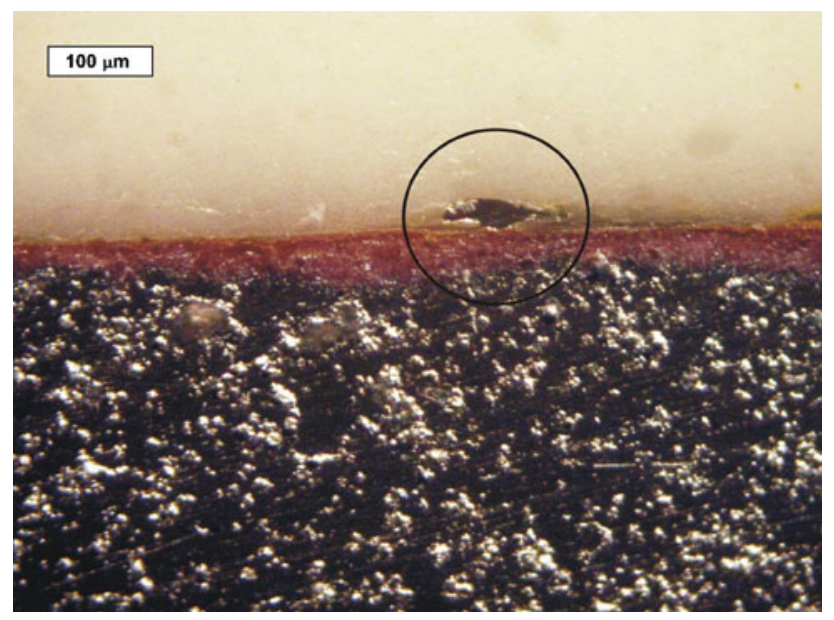

Fig. 12 Micrograph of a cross-section of $\mathrm{CoSb}_{3}$ oxidized sample with a platinum marker (inside a black circle)

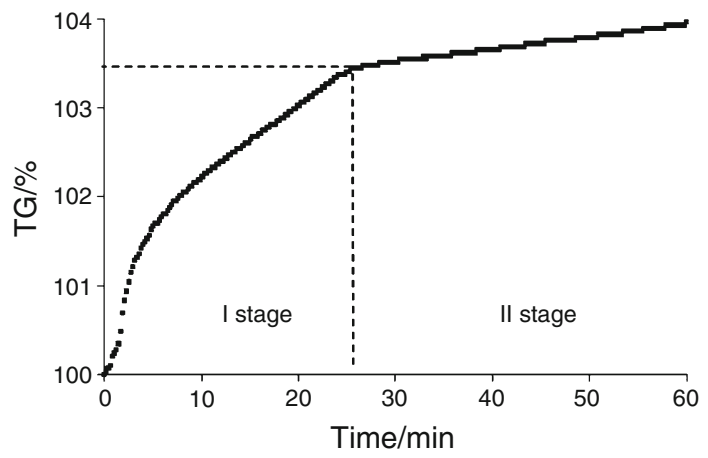

Fig. 13 Example of isothermal oxidation curve of $\mathrm{CoSb}_{3}$ powder (air, $470{ }^{\circ} \mathrm{C}, 120 \mathrm{mg}$ )

X-ray diffraction patterns results were presented by Hara et al. [5]. This apparent difference in microscopic observations and EDS analysis could be explained by a low resolution and a high noise level of the EDS analysis and relatively small differences of the concentration of elements between both cobalt antimonates. The average thickness ratio between the inner(IIb) and middle(IIa) layer is about 4:1 for a specimen oxidized at $600{ }^{\circ} \mathrm{C}$. Local thickness ratio, alike the total thickness, differs from place to place in each sample. In order to determine the dominant mass transport direction during the oxidation a marker experiment has been performed. Figure 12 shows a cross-section of a sample after oxidation with the marker, the marker is highlight by black circles. The markers is placed inside the $\mathrm{Sb}_{2} \mathrm{O}_{4}$ layer at the interface with $\mathrm{CoSb}_{2} \mathrm{O}_{6}$. This indicates that in the outer layer an outward antimony diffusion is dominating. The mass transport through $\mathrm{CoSb}_{2} \mathrm{O}_{6}$ and $\mathrm{CoSb}_{2} \mathrm{O}_{4}$ involves an inward oxygen flux and an outward antimony flux. It seems that cobalt atoms are the least mobile species creating a rigid framework of cobalt antimonates.

\section{Oxidation kinetics}

Keeping in mind the likely working temperatures for $\mathrm{CoSb}_{3}$ as well as the TG and DTA results, temperature range $410-550{ }^{\circ} \mathrm{C}$ was selected for kinetic studies. Two series, named $\mathrm{A}$ and $\mathrm{B}$ of $\mathrm{CoSb}_{3}$ oxidation experiments, were performed. A representative isothermal oxidation curve is presented in Fig. 13. The oxidation proceeds in two stages. The mass gain of the completion of the first stage depended on a grain size, therefore this process is a product thickness dependent. The average total weight gain of the I stage for the first A-series was 3.5\% and for the second B-series of experiments, for a more fine-grained powder with the average grain size $15 \mu \mathrm{m}$ it was about $10 \%$. In order to determine the best fit of the kinetic model for the first stage, fractional extent of reaction $\alpha$ was calculated using mass-gain relative to the total mass-gain for the first stage completion. Analysis of induction period of the oxidation curves has shown that this period corresponds to undefined conditions during the specimen temperature equilibration and it can not be used in a kinetic analysis. After exclusion of the induction period the remaining part of the oxidation curves has deceleratory character. The range of $\alpha$ used in the kinetic studies was 0.1 to 0.95 , where the bottom $\alpha$ limit was determined, as before mentioned, by a time necessary to reach the fixed temperature. In order to select the best kinetic equation for the observed $\alpha$-time set, a linearity of $g(\alpha)=k t$ plots against time was tested. Statistical criterions for a judgement of the fit were correlation coefficient $r$, standard deviation $\sigma$ of $k$ divided by $k-\sigma / k$, and a sum of squared error SSE between measured and estimated fractional reaction $\left(\alpha_{\exp }-\alpha_{\text {calc }}\right)^{2}$. Due to a deceleratory type of the oxidation curves, mainly deceleratory kinetic models for the solid-state reactions were selected for the kinetic analysis. According to the controlling processes, these models can be divided in three groups: geometrical models, "order of reaction" models and diffusion models, where some of the diffusion models-Jander and Ginstling Brounshtein are a combination of diffusion and geometrical model. The models used in the analysis are listed in Table 3 and results of the analysis are presented in Table 4 . The best fit was found for a rate equation of one-dimensional diffusion known as the parabolic law $\alpha=(k t)^{1 / 2}$. For each criterion which were used, the parabolic law gave the best quality of the fit. Figure 14 shows an example oxidation curve fit with different kinetic equations. A $\alpha_{\text {Dicalc. }}-\alpha_{\text {exp }}$ difference plot (Fig. 14) of the experimental and calculated fractional reaction for the parabolic law demonstrates that there is no significant systematic deviation between the observed $\alpha$-time set and the parabolic model. Testing of the linearity of the massgain plots versus $t^{1 / 2}$ (Fig. 15) showed that the parabolic law is also well describing the second stage of the 
Table 3 Selected kinetic models used in the kinetic analysis of the oxidation

\begin{tabular}{llll}
\hline Name & & Description & $g(\alpha)=k t$ \\
\hline Parabolic law & D1 & One-dimensional diffusion & $\alpha^{2}$ \\
& D2 & Two-dimensional diffusion & $(1-\alpha)[-\ln (1-\alpha)]+\alpha$ \\
Jander & D3 & Three-dimensional diffusion & {$\left[1-(1-\alpha)^{1 / 3}\right]^{2}$} \\
Ginstling-Brounshtein & D4 & Three-dimensional diffusion & $1-2 / 3 \alpha-(1-\alpha)^{2 / 3}$ \\
Contracting area & R2 & Two-dimensional interface advance & $1-(1-\alpha)^{1 / 2}$ \\
Contracting volume & R3 & Three-dimensional interface advance & $1-(1-\alpha)^{1 / 3}$ \\
First order & F1 & First order reaction & $-\ln (1-\alpha)$ \\
Second order & F2 & Second order reaction & $(1-\alpha)^{-1}-1$ \\
\hline
\end{tabular}

Equations are in the integral form $g(\alpha)=k t$, and models labels are according with Sharp's labelling

Table 4 Kinetic analysis results for the first stage of the oxidation

\begin{tabular}{lrllll}
\hline Symbol & $r$ & SSE & $\sigma / k$ & $E_{\mathrm{a}(\mathrm{I})} / \mathrm{kJ} / \mathrm{mol}$ & $\ln k_{0(\mathrm{I})}$ \\
\hline Series A & & & & & \\
D1 & 0.9937 & 1.24 & 0.0067 & 161 & 21.60 \\
D2 & 0.9064 & 3.13 & 0.0540 & 162 & 21.45 \\
D3 & 0.9669 & 3.60 & 0.0181 & 169 & 21.58 \\
D4 & 0.9790 & 2.51 & 0.0153 & 161 & 21.96 \\
R2 & 0.9846 & 1.46 & 0.0120 & 162 & 21.49 \\
R3 & 0.9884 & 1.64 & 0.0098 & 163 & 21.40 \\
F1 & -0.9866 & 2.44 & 0.0608 & 166 & 23.21 \\
Series B & & & & & \\
D1 & 0.998 & 0.08 & 0.003 & 168 & 23.26 \\
D2 & 0.914 & 1.8 & 0.115 & 183 & 25.11 \\
D3 & 0.904 & 1.1 & 0.096 & 169 & 22.63 \\
D4 & 0.963 & 0.12 & 0.018 & 174 & 24.45 \\
R2 & 0.993 & 0.13 & 0.007 & 172 & 23.58 \\
R3 & 0.984 & 0.28 & 0.018 & 172 & 23.33 \\
F1 & -0.927 & 4.7 & 0.496 & 172 & 25.01 \\
\hline
\end{tabular}

$r$ linear correlation coefficient, $S S E$ average sum of squared error, $\sigma / \mathrm{k}$ standard deviation to reaction rate ratio, $E_{\mathrm{a}(\mathrm{I})}$ activation energy, $\ln k_{0(\mathrm{I})}$ $1 / T$

oxidation. Activation energies $E_{\mathrm{a}}$ were calculated, assuming the one-dimensional diffusion equation. For the first stage the calculated activation energy was $E_{\mathrm{a}(\mathrm{I})}=161 \pm$ $15 \mathrm{~kJ} / \mathrm{mol}$ for the A-series and $168 \pm 21 \mathrm{~kJ} / \mathrm{mol}$ for the B-series and for the second stage $E_{\mathrm{a}(\mathrm{II})}=106 \pm 9 \mathrm{~kJ} / \mathrm{mol}$ for the B-series. Due to a large number of scale cracking features present on the oxidation curves, the second stage oxidation curves from the A-series were not analysed.

Discussion of $\mathrm{CoSb}_{3}$ oxidation results

Based on the XRD and SEM observations it was established that $\alpha-\mathrm{Sb}_{2} \mathrm{O}_{4}, \mathrm{CoSb}_{2} \mathrm{O}_{6}$ and $\mathrm{CoSb}_{2} \mathrm{O}_{4}$ are the main oxidation products. However, the presence of other intermediate products indicates that cobalt triantimonide oxidation is a complex process and different reactions can proceed in parallel. The $\mathrm{CoSb}_{3}$ decomposition to cobalt diantimonide may be a competitive process, only at higher temperatures, when oxygen transport may limit the oxidation reaction. It is less probable that oxidation proceeds through a step of decomposition into $\mathrm{CoSb}_{2}$ because the starting temperature of the oxidation is lower than the starting temperature of the decomposition.

On the basis of the kinetic results, the microscopic observations and the phase composition, we can say that the rate limiting step of both stages of the $\mathrm{CoSb}_{3}$ oxidation is a diffusion of reactants through the growing layers of products. Although, the oxidation kinetic measurements were performed on powder samples, no influence of changing reaction surface in the kinetic was observed for the first stage of the reaction. Different kinetic parameters for the fist and the second oxidation stage indicate a change of the rate limiting step between the first and the second stage. If we keep in mind the microscopic results and the $\mathrm{XRD}$ results, the first stage can be ascribed to a formation of a composite mixture of the antimony oxide and cobalt antimonites and its subsequent reorganization into three layer scale. When this transformation is completed and the products have formed continues and compact layers, the second stage is started and it can be ascribed to the growth of the three-layered scale. Using the observed mass-gain for the completion of the first stage, the average grain size, $\mathrm{CoSb}_{3}$ and the oxidation products densities and a simple geometrical relation the scale thickness for the completion of the first stage was estimated to be about $4.5-5 \mu \mathrm{m}$. The oxidation rate constant of the first stage is higher than the oxidation rate constant of the second stage. It can be explained in a following way. During the first stage a parallel diffusion through all the products occurs, therefore, the oxidation rate for the first stage is limited by the slowest step of the reactants transport through a product, for which the reactants transport is the fastest. During the second stage a successive diffusion through each of the layers occurs, thus for the second stage the rate constant is limited 


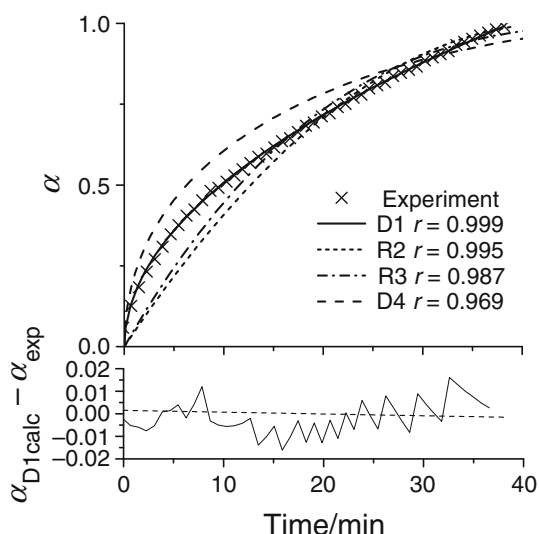

Fig. 14 Sample $\mathrm{CoSb}_{3}$ oxidation curve with fits of some of the selected models to the experimental data. Crosses corresponds to experimental data and lines are the fits with: D1-parabolic law, R2-contracting area, R3-contracting volume, D4-GinstlingBrounstein equations. The calculated correlation coefficients for the

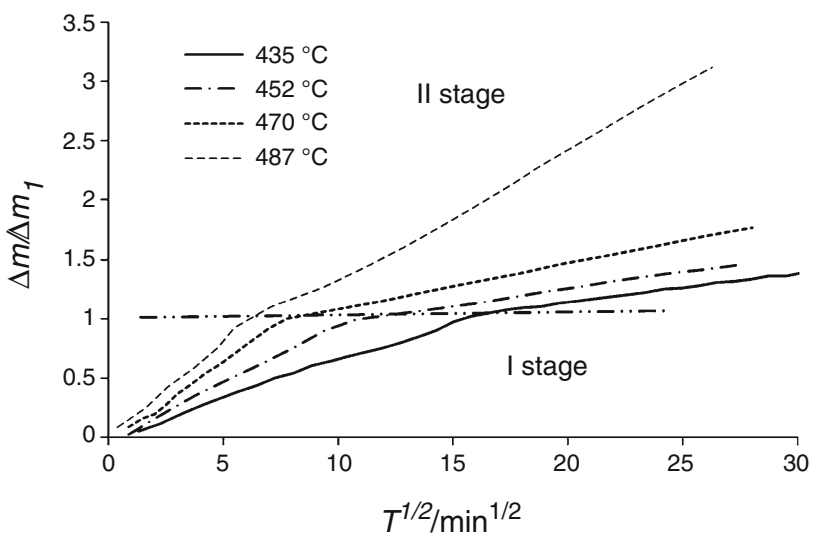

Fig. 15 Oxidation curves in a linearizing coordination system for the parabolic law (mass-gain related to the mass-gain for the first oxidation stage completion)

by the slowest step of a reactant diffusion in a product, where the diffusion is slowest. During the first stage of the oxidation when the products are mixed their volume is higher than the volume of skuttetrudite substrate. The consequence of this fact is a stress at the scale-metal interface, resulting in a scale cracking and a 'breakaway' linear oxidation which is observed on some oxidation curves at the final period of the first oxidation stage and at the beginning of the second stage. When the products are well split into three distinct layers, the volume difference at the scale/substrate interface between $\mathrm{CoSb}_{2} \mathrm{O}_{4}$ layer and the $\mathrm{CoSb}_{3}$ substrate is reduced and no scale cracking features are observed. This is in good agreement with the microscopic observations, which show that the scale cracking takes place for layers thinner than $7 \mu \mathrm{m}$. For bulk samples and long oxidation times the scale was always well

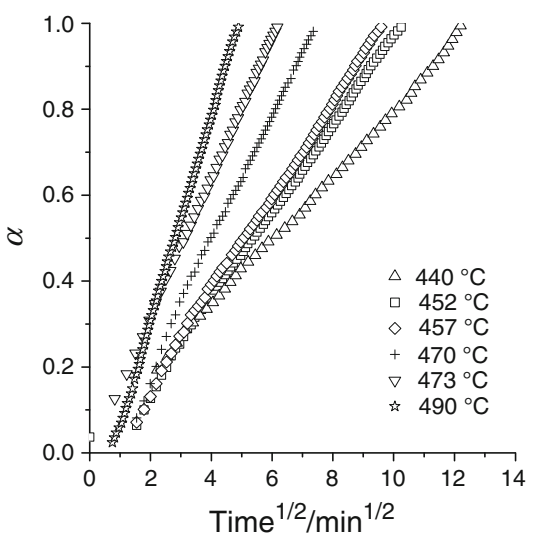

fits are also included. The bottom curve is a difference between the $\alpha$ calculated for the parabolic law and the measured $\alpha$. The second plot presents oxidation curves of A-series in a linearizing coordinate system for the parabolic law

adherent to substrate. While comparing antimony oxidation state in the products one can find interesting that the oxidation state of antimony is lower in the outer layer of $\mathrm{Sb}_{2} \mathrm{O}_{4}(+3,+5)$ than in the middle layer of $\mathrm{CoSb}_{2} \mathrm{O}_{6}(+5)$. It can be explained by a low thermodynamic stability of antimony (+5) oxide $\mathrm{Sb}_{2} \mathrm{O}_{5}$, which at this temperature range and for these oxygen partial pressures decompose to the most stable $\alpha-\mathrm{Sb}_{2} \mathrm{O}_{4}$. For the second stage of the oxidation we propose a set of three equations to describe the reactions undergoing on the successive interfaces:

$2 \mathrm{Sb}^{3+}+2 \mathrm{O}_{2}+6 \mathrm{e}^{-}=\mathrm{Sb}_{2} \mathrm{O}_{4}$

$\mathrm{CoSb}_{2} \mathrm{O}_{4}+2 \mathrm{O}^{2-}=\mathrm{CoSb}_{2} \mathrm{O}_{6}+4 \mathrm{e}^{-}$

$\mathrm{CoSb}_{3}+4 \mathrm{O}^{2-}=\mathrm{CoSb}_{2} \mathrm{O}_{4}+\mathrm{Sb}^{3+}+11 \mathrm{e}^{-}$

As the defect structure is not known for any of these compounds, these equations represent general redox reactions. They are not reflecting the mechanism of the reactions and they are not pointing out species participating in the reaction and in the mass and charge transport undergoing in the scale. The overall oxidation can be expressed as:

$$
\begin{aligned}
\mathrm{CoSb}_{3}+(2 x+3 y+1) \mathrm{O}_{2(g)}= & x \operatorname{CoSb}_{2} \mathrm{O}_{4}+y \operatorname{CoSb}_{2} \mathrm{O}_{6} \\
& +1 / 2 \mathrm{Sb}_{2} \mathrm{O}_{4}
\end{aligned}
$$

where $x+y=1$. Our results show some differences compared to what have been found by Hara et al. They have proposed a model of oxidation in which the first step is antimony segregation followed by an oxygen diffusion into Sb-rich region and finally the reaction. The absence of $\mathrm{CoSb}_{2}$ (we have observed cobalt diantimonide only as a product of a competitive reaction at a temperature $700{ }^{\circ} \mathrm{C}$ and above) does not support their model. Together with the fact that the starting temperature of the oxidation and of the 


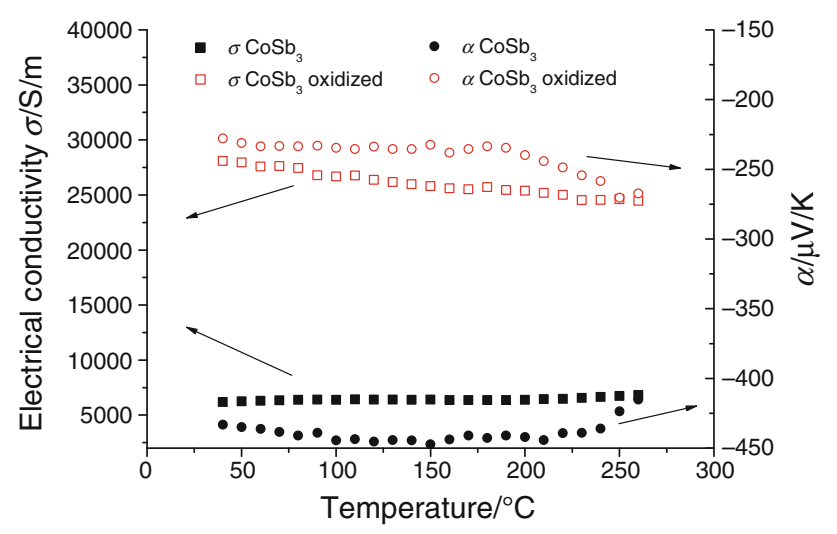

Fig. 16 Electrical conductivity temperature dependence and Seebeck coefficient temperature dependence of $\mathrm{CoSb}_{3}$ samples before and after the oxidation (air, $615^{\circ} \mathrm{C}, 48 \mathrm{~h}$ )

decomposition is different, it points out that the oxidation do not proceed through a simple decomposition, and oxygen plays a role in weakening and breaking of the chemical bonds in $\mathrm{CoSb}_{3}$.

\section{Thermoelectric results}

For a thermoelectric generator one can define a material parameter which is linked with the energy conversion efficiency of the thermoelectric material, so-called thermoelectric figure-of-merit $Z$. This $Z$ parameter expresses a set of desirable material properties for a good thermoelectric material, and it is:

$Z=\frac{\sigma \alpha^{2}}{\lambda} / K^{-1}$

where $\sigma$ is electrical conductivity, $\alpha$ is thermoelectric power, and $\lambda$ is thermal conductivity. The higher value of the $Z$ parameter the better thermoelectric properties has a thermoelectric material. In some cases it is useful to exclude thermal conductivity from the figure of merit and then a parameter called power factor $\mathrm{PF}=\alpha^{2} \sigma$ is used to compare thermoelectric properties of different materials.

In order to determine influence of the degradation in the oxidising atmosphere on $\mathrm{CoSb}_{3}$, measurements of the electric conductivity and the Seebeck coefficient of a sample before and after heating in air were performed. The thermal treatment was carried out at $615^{\circ} \mathrm{C}$ for 2 days, after that the measured mass-gain of the specimen was $3 \%$ and the total thickness of the oxidation products was approximately $60 \mu \mathrm{m}$. In Fig. 16 the electrical conductivity $\sigma$ temperature dependence before and after $\mathrm{CoSb}_{3}$ oxidation is presented. It can be seen that the oxidation caused a six-fold increase of $\sigma$ from $6 \times 10^{3}$ to $4 \times 10^{4} \mathrm{~S} / \mathrm{m}$. The Seebeck coefficient absolute value is decreased twice so the resulting effect on the power factor $\alpha^{2} \sigma$ is balanced by the electrical conductivity rise. From a simple calculation it seems that for the pure $\mathrm{CoSb}_{3}$ the oxidation improved the thermoelectric properties, but it should be remembered that in an optimized material each carrier concentration change and a resulting $\alpha$ and $\sigma$ change is disadvantageous. Moreover, for longer oxidation times the influence on the thermoelectric power would be enhanced and the apparent improvement will disappear.

\section{Conclusions}

Results of the preliminary investigation show that $\mathrm{CoSb}_{3}$ is not chemically stable above $400{ }^{\circ} \mathrm{C}$. The decomposition in vacuum or in an inert atmosphere first proceeds to a formation of $\mathrm{CoSb}_{2}$ layer covering the substrate and at higher temperatures or lower oxygen pressures in the next step it can decompose to $\mathrm{CoSb}$. The oxidation leads in two stages to a formation of a complex three-layered scale consisting of $\mathrm{CoSb}_{2} \mathrm{O}_{4}, \mathrm{CoSb}_{2} \mathrm{O}_{6}$ and $\alpha-\mathrm{Sb}_{2} \mathrm{O}_{4}$. During the oxidation, as well as during the decomposition, grain boundaries seem to play an important role in enhancement of the mass transport. Decomposition as well as both oxidation stages are diffusion controlled and can be described by the parabolic law. Thermoelectric properties were determined before and after oxidation and showed that thermal degradation has great influence on the thermoelectric properties of $\mathrm{CoSb}_{3}$. The application of the $\mathrm{CoSb}_{3}$ based materials in the thermoelectric devices at high temperatures is possible if the decomposition or oxidation rate would be suppressed by applying, e.g. hermetic covers or protective coatings on the thermoelectric elements.

Acknowledgements This study was supported by Polish Ministry of Scientific Research and Higher Education (grant No. 11.11.160.110).

Open Access This article is distributed under the terms of the Creative Commons Attribution Noncommercial License which permits any noncommercial use, distribution, and reproduction in any medium, provided the original author(s) and source are credited.

\section{References}

1. Hanninger G, Ipser H, Terzieff P, Komarek KL. The Co-Sb phase diagram and some properties of NiAs-Type $\mathrm{Co}_{1 \pm x} \mathrm{Sb}$. J LessCommon Met. 1990;166:103-14.

2. Uher C, Shi X, Kong H, Mater. Res. Soc. Symp. Proc. 2008; 1044; Materials Research Society 1044-U05-09.

3. Lamberton GA, Bhattacharya S, Littleton RT IV, Kaeser MA, Tedstrom RH, Tritt TM, Yang J, Nolas GS. High figure of merit in Eu-filled CoSb3-based skutterudites. Appl Phys Lett. 2002; 80:598-600.

4. Puyet M, Dauscher A, Lenoir B, Dehmas M, Stiewe C, Müller E, Hejtmanek J. Beneficial effect of $\mathrm{Ni}$ substitution on the 
thermoelectric properties on partially filled CayCo4-xNixSb12 skutterudites. J Appl Phys. 2005;97:083712.

5. Pei YZ, Chen LD, Zhang W, Shi X, Bai SQ, Zhao XY, Mei ZG, $\mathrm{Li} X Y$. Synthesis and thermoelectric properties of $\mathrm{K}_{y} \mathrm{Co}_{4} \mathrm{Sb}_{12}$. Appl Phys Lett. 2006;89:221107.

6. Savchuk V, Boulouz A, Chakraborty S, Schumann J, Vinzelberg $\mathrm{H}$. Transport and structural properties of binary skutterudite $\mathrm{CoSb}_{3}$ thin films grown by dc magnetron sputtering technique. J Appl Phys. 2002;92:5319-26.

7. Hara R, Inoue S, Kaibe HT. Aging effects of large-size n-type $\mathrm{CoSb}_{3}$ prepared by spark plasma sintering. J Alloy Compd. 2003; 349:297-301.

8. Leszczynski J, Malecki AL, Wojciechowski KT, Proceedings of the $5^{\text {th }}$ European Conference on Thermoelectrics, Odessa, Ukraine, September 10-12, 2007.
9. Snyder GJ, Caillat T, High Efficiency Thermoelectrics Workshop San Diego, California February 17-20, 2004.

10. Wojciechowski KT. Effect of tellurium doping on the thermoelectric properties of $\mathrm{CoSb}_{3}$. Mater Res Bull. 2002;37:2023-34.

11. Agrawal YK, Shashimohan AL, Biswas AB. Studies on antimony oxides. Part I: Thermal analysis of $\mathrm{Sb}_{2} \mathrm{O}_{3}$ in air, nitrogen and argon. J Therm Anal. 1975;7:635-41.

12. Filipek E, Wieczorek-Ciurowa K. Comparison between the synthesis in molybdenum and antimony oxides system by hightemperature treatment and high-energy ball milling. J Therm Anal Calorim. 2009;97:105-10.

13. Filipek E, Dạbrowska G. Unknown thermal properties of $\mathrm{ZnSb}_{2} \mathrm{O}_{6}$ and $\mathrm{Zn}_{7} \mathrm{Sb}_{2} \mathrm{O}_{12}$ compounds. Reactivity of $\alpha$-Sb2O4 with $\mathrm{ZnO}$ on heating in air. J Therm Anal Calorim. 2008;94(1): 195-201. 